\title{
Age-dependent Increase in Desmosterol Restores DRM Formation and Membrane-related Functions in Cholesterol-free DHCR24 $^{-\prime-}$ Mice
}

\author{
Katrin Kuehnle $\cdot$ Maria D. Ledesma $\cdot$ Lucie Kalvodova $\cdot$ Alicia E. Smith · \\ Arames Crameri · Fabienne Skaanes-Brunner · Karin M. Thelen · Luka Kulic • \\ Dieter Lütjohann · Frank L. Heppner · Roger M. Nitsch · M. Hasan Mohajeri
}

Accepted: 5 December 2008/Published online: 25 December 2008 (C) Springer Science+Business Media, LLC 2008 processes that are normally cholesterol-dependent including formation of DRMs from mouse brain extracts, membrane receptor ligand binding and activation, and regulation of membrane protein proteolytic activity. These data indicate that desmosterol can replace cholesterol in membranerelated functions in the DHCR $24^{-1-}$ mouse.

Keywords BACE - Cholesterol - Seladin-1 - Plasmin · Proteoliposomes $\cdot$ Sterols $\cdot$ GM1

\section{Introduction}

Cholesterol plays a key role in regulating the fluidity of mammalian cell membranes and functions in a variety of cellular processes including molecular sorting and signaling, as well as protein synthesis, maturation, activity and degradation [1-3]. Many pathological conditions, including Alzheimer's disease (AD), are associated with abnormalities of cholesterol-related functions $[4,5]$. Cholesterol biosynthesis follows two intersecting routes: the Bloch

The online version of this article (doi:10.1007/s11064-008-9893-4) contains supplementary material, which is available to authorized users.

K. Kuehnle · A. Crameri · F. Skaanes-Brunner · L. Kulic ·

R. M. Nitsch - M. H. Mohajeri

Division of Psychiatry Research, University of Zurich,

8008 Zurich, Switzerland

M. D. Ledesma

Centro de Biología Molecular Severo Ochoa,

28049 Madrid, Spain

L. Kalvodova

Max-Planck Institute of Molecular Cell Biology and Genetics,

01307 Dresden, Germany

A. E. Smith

Institue of Biochemistry, ETH-Hönggerberg, 8093 Zurich,

Switzerland
K. M. Thelen · D. Lütjohann

Department of Clinical Pharmacology, University of Bonn,

53105 Bonn, Germany

\section{F. L. Heppner}

Institute for Neuropathology, Charité-Universitätsmedizin

Berlin, 13353 Berlin, Germany

Present Address:

M. H. Mohajeri

DSM Nutritional Products, 4002 Basel, Switzerland

K. Kuehnle $(\bowtie)$

Swiss Academy of Medical Sciences, Petersplatz 13, 4051 Basel, Switzerland

e-mail:k.kuehnle@samw.ch 
synthesis pathway with desmosterol as the immediate precursor of cholesterol and the Kandutsch-Russell pathway with 7-dehydrocholesterol as the direct precursor [6]. The $3 \beta$-hydroxysterol- $\Delta 24$ reductase (DHCR24/seladin-1) is crucial for cholesterol biosynthesis, because it is the mediating enzyme between the two pathways, reducing the C24 double bonds of Bloch-pathway precursors, finally leading to formation of cholesterol. Mutations in the dhcr 24 gene resulting in the limited ability to convert desmosterol to cholesterol, lead to a human metabolic disorder, desmosterolosis. This rare malformation syndrome is characterized by severe developmental defects and cognitive impairment. In contrast, mice with a targeted disruption in the dhcr 24 gene (DHCR24 ${ }^{-l-}$ mice) have an unexpectedly mild phenotype, being small and infertile but viable. These mice are essentially cholesterol-free, and desmosterol was shown to account for 99\% of all sterols [7-9], raising the question whether desmosterol can functionally replace cholesterol in vivo.

Cholesterol is required for the structural integrity of lipid raft microdomains [10]. Membrane rafts are small (10-200 nm), heterogeneous, highly dynamic, sterol- and sphingolipid-rich domains that compartmentalize cellular processes and that can be stabilized to form larger platforms through protein-protein and protein-lipid interactions [11]. Up to date, there is no biochemical method for isolation of lipid rafts. However, since lipid rafts are assumed to exist in liquid-ordered state, and since lipid membranes in an ordered state exhibit higher resistance to solubilization with non-ionic detergents than disorder membranes [12], the composition of cellular rafts will, to some degree, be reflected by the composition of the so-called detergent-resistant membranes, or DRMs. DRMs are prepared by solubilization of cell membranes in Triton $\mathrm{X}-100$ at $4^{\circ} \mathrm{C}$ followed by separation of the soluble and insoluble material on a density gradient. The DRM fraction is the lipid-rich, but insoluble fraction of cell membranes, obtained as the floating fraction.

Membrane active sterols are important for regulation of membrane fluidity and in addition, some sterols are responsible for promoting liquid-ordered phase formation. Under physiological conditions, cholesterol is the only sterol extensively available in mammalian membranes and as such is an indispensable component of the membrane and of lipid rafts.

Nevertheless, in addition to cholesterol, several other sterols including lathosterol and desmosterol are membrane-active sterols, defined as sterols that decrease membrane permeability and increase the order in the lipid acyl chains near the terminal methyl group, among other factors [13, 14]. Lathosterol, a more distant precursor of cholesterol, associates with rafts at least as efficiently as cholesterol $[15,16]$. Desmosterol has similar effects on membrane lipid order, phase separation and lipid packing in model membranes as compared to cholesterol $[17,18]$. Moreover, it was shown that desmosterol could substitute for cholesterol in maintaining cell growth, membrane integrity and preserving caveolar invaginations in vitro [19]. Therefore, desmosterol appears to be a candidate for a sterol capable of substituting cholesterol in membranerelated functions in vivo.

Generation of the amyloid- $\beta(\mathrm{A} \beta)$ peptide is a membrane-related event involving the transmembrane substrate APP that is metabolized by integral membrane proteases, the $\beta$-secretase (BACE) cleaving at the $\mathrm{N}$ terminus, and the $\gamma$-secretase complex cleaving within the transmembrane domain at the $\mathrm{C}$ terminus of $\mathrm{A} \beta$ [20]. Rafts contribute to the segregation of APP from BACE [7, 21]. While endogenous APP and $\alpha$-secretases were predominantly found in membrane compartments not associated with lipid rafts, BACE and the $\gamma$-secretase complex were shown to reside within rafts of late Golgi and early endosomes [2224]. Hence, access of $\alpha$ - and $\beta$-secretase to APP and A $\beta$ generation are likely determined by dynamic interactions of APP and its secretases with lipid rafts. Reduction of cholesterol up to $30 \%$ cause raft disorganization, leading to increased $\beta$-cleavage and higher $\mathrm{A} \beta$ production $[7,25]$. Therefore, rafts may separate APP from the $\gamma$-secretase complex and BACE under physiological conditions, and disruption of rafts through cholesterol depletion could impair the sequestration of $\gamma$-secretase and BACE from APP resulting in higher rates of APP cleavage by these secretases $[7,25,26]$. These data suggest that proper raft organization is required to maintain the steady state levels of $\mathrm{A} \beta$. Importantly, further depletion of cholesterol to a degree $>30 \%$ results in elevated levels of $\operatorname{sAPP} \alpha$, reduced $\beta$-cleavage and diminished $\mathrm{A} \beta$ production [21, 27-30]. In these studies, cholesterol-lowering drugs and/or cholesterol-extracting agents were used to reduce cellular and membrane cholesterol levels, a procedure that is likely to affect the functional integrity of involved secretases.

In the present work, we determined the effects of DHCR24 deficiency on brain sterol metabolism and we analyzed the distribution of Bloch and Kandutsch-Russel sterols in brains of 3- and 16-week-old DHCR $24^{-1-}$ mice. Knock-out mice of both age-groups were largely devoid of brain cholesterol, while desmosterol accounted for $\sim 50 \%$ of the lacking cholesterol concentrations in 3-week-old DHCR $24^{-1-}$ mice. In 16-week-old mice, a complete substitution of cholesterol by desmosterol was determined, with equimolar concentrations of desmosterol in knock-out brains compared to cholesterol levels in wild type (wt) mice.

In order to evaluate the consequences of a chronic cholesterol deficiency on membrane organization we analyzed protein and lipid composition of DRMs in brains of 
3- and 16-week-old DHCR24 ${ }^{-1-}$ mice. To assess the functional relevance of cholesterol paucity, we studied plasmin activation and APP processing as two examples of membrane-dependent proteolyses. In brains of 3-week-old DHCR $24^{-l-}$ mice, membrane composition differed considerably from that of wt controls, as indicated by a major disruption of DRMs. Moreover, membrane-related proteolytic functions were substantially altered as indicated by reduced plasmin activity, lower $\beta$-secretase activity and diminished $\mathrm{A} \beta$ generation. In contrast, age-related desmosterol accumulation and integration in membranes of 16-week-old DHCR $24^{-1-}$ mice led to the formation of desmosterol containing DRMs, recruitment of raft-specific proteins in DRM compartments, restoration of secretase activity and therefore physiological $\mathrm{A} \beta$ generation. Furthermore, desmosterol stimulated proteolytic activity of BACE reconstituted in proteoliposomes to a comparable extent as cholesterol.

These data show that desmosterol-when it is present in the DHCR $24^{-1-}$ mouse brain as abundantly as naturally occurring cholesterol-integrated into membranes and facilitated formation of desmosterol-dependent DRMs that contain specific membrane proteins, which normally associate with cholesterol-containing DRMs. Our data further show that an age-dependent increase in desmosterol in DHCR $24^{-1-}$ mice restored proteolytic activity of BACE in the absence of cholesterol and efficiently replaced cholesterol in membrane-associated processes that are normally cholesterol dependent.

\section{Experimental Procedures}

Mice

A heterozygous breeding pair with target depletion of one DHCR24 allele was received from Dr. E. Feinstein (Quark Biotech Inc.). Mice were bred and genotyped as described [9]. All animal experiments and husbandry were performed compliant with national guidelines and were approved by the veterinarian authorities of the Canton of Zurich.

\section{Histology}

Mice were perfused transcardially under deep anesthesia (ketamin $100 \mathrm{mg}$, xylazine $5 \mathrm{mg} / \mathrm{kg}$ bodyweight, i.p.) using a peristaltic pump. Perfusion was performed initially with chilled PBS pH 7.4 for 10-15 min, followed by perfusion with $4 \%$ PFA. Brains were removed and immersionfixed in $4 \%$ PFA overnight at $4{ }^{\circ} \mathrm{C}$. After extensive washing with PBS, the fixed tissue fragments were dehydrated through a graded series of ethanol solutions followed by xylene incubation and embedded in paraffin before cutting histological sections of the cortex. Specimens $(5 \mu \mathrm{m})$ were washed in xylene, rehydrated and stained with hematoxylin and eosin $(\mathrm{H} / \mathrm{E})$ or Luxol fast blue according to standard protocols. Apoptotic cells were detected performing immunohistochemistry with an antibody against cleaved caspase-3 Asp 175 (cell signaling) following the manufacturer's instructions. Terminal deoxynucleotidyl transferase mediated dUTP nick end labeling assay (TUNEL, purchased from Roche) was performed according to the manufacturer's protocol.

\section{Tissue Preparation}

Mouse brains ( $n=5$ per group) were homogenized in a Tris-Buffer containing 2\% SDS with complete protease inhibitors (Roche) in a dounce homogenizer for $5 \mathrm{~min}$ on ice. The samples were centrifuged at $100,000 \mathrm{~g}$ for $1 \mathrm{~h}$ at $8^{\circ} \mathrm{C}$ to pellet the insoluble debris. The supernatant was considered as total homogenate and used for Western blot analyses. Protein concentration was quantified using the DC protein assay (BIORAD). Detergent extraction and DRM isolation were performed as described [7]. In brief, mouse brains ( $n=3-4$ per group) were homogenized in 9\% sucrose in PBS containing protease inhibitors in a dounce homogenizer using 10 strokes and 10 passages through a 22-gauge syringe on ice. The samples were centrifuged at $700 \mathrm{~g}$ for $10 \mathrm{~min}$ to pellet the debris and the supernatant was considered as total brain extracts. 300 $400 \mu \mathrm{g}$ protein of brain extracts were incubated for $1 \mathrm{~h}$ at $4^{\circ} \mathrm{C}$ in $1 \%$ Triton $\mathrm{X}-100,25 \mathrm{mM}$ MES $\mathrm{pH} 7.0,5 \mathrm{mM}$ DTT, $2 \mathrm{mM}$ EDTA and protease inhibitors. The extracts were mixed with $90 \%$ sucrose prepared in MBS buffer (25 mM MES, pH 7.0, $150 \mathrm{mM} \mathrm{NaCl}$ and protease inhibitors) over layered with a step gradient of 35 and 5\% sucrose in MBS. After centrifugation at 100,000 $g$ for $18 \mathrm{~h}$ at $4^{\circ} \mathrm{C}$, fractions $4-6$ were identified as the DRM fraction by the presence of the DRM markers flotillin-1 and $\operatorname{Prp}^{\mathrm{c}}$ in the control samples.

\section{Primary Neuronal Cultures}

Primary cultures of cortical neurons from DHCR24 $4^{-1-}$ and wt mice were prepared from embryos as described [31]. Neurons (glial contamination $<5 \%$ ) were cultured in cholesterol-free Neurobasal-Medium supplemented with B27 (Invitrogen). For detection of $\mathrm{A} \beta$ in supernatants of primary neurons medium was changed $24 \mathrm{~h}$ before harvest. Medium was removed from primary neurons that were cultured for 4 or 8-10 days. $150 \mu$ of the supernatant was then used for ELISA without further processing. For sterol measurements, neurons cultivated for 4, 6 and 8-10 div were washed and scraped in PBS. Total sterols were extracted and measured as described below. Cell viability 
of primary neurons was determined using the MTT and the LDH assay (both from Sigma) according to the manufacturer's instructions.

For immunohistochemistry, neurons were fixed with $4 \%$ PFA for $10 \mathrm{~min}$ at room temperature, blocked and permeabilized with $5 \%$ horse serum containing $0.1 \%$ Triton $\mathrm{X}-100$ for $2 \mathrm{~h}$. Anti-Map2 antibody and anti GFAP antibody (both from Sigma) were used to determine the percentage of neurons and astrocytes according to the manufacturer's instructions. In addition, Map-2 staining was used to check cell morphology and viability of wt and DHCR24 $4^{-1-}$ neurons. Species specific fluorescencelabeled secondary antibodies (Amersham) were diluted in blocking buffer and cells were stained for $2-4 \mathrm{~h}$ in the dark. For analysis, cells were washed in PBS and embedded in Moviol (Merk).

Choleratoxin $\beta$ Subunit Binding and Internalization Assay

For all experiments using Choleratoxin $\beta$ subunit, primary neurons were cultured in 8-well coverglass chambers (Labtek) previously coated with polyornithin/laminin (Sigma) in sterol-free medium for 6-8 days. For plasma membrane binding experiments, $200 \mu \mathrm{l}$ of culture media containing FITC-labeled Choleratoxin- $\beta$ (Sigma) at a concentration of $1 \mu \mathrm{g} / \mathrm{ml}$ was added for $2 \mathrm{~min}$ at room temperature. Neurons were washed twice with culture media and directly visualized. For internalization experiments, neurons were incubated in culture media containing FITC-labeled Choleratoxin- $\beta$ (Sigma) at a concentration of $1 \mu \mathrm{g} / \mathrm{ml}$ for $2 \mathrm{~min}$ at room temperature. Neurons were washed twice with culture media, and cultured for $30 \mathrm{~min}$ at $37^{\circ} \mathrm{C}$ in a $\mathrm{CO}_{2}$ incubator $(5 \% \mathrm{v} / \mathrm{v})$. The culture chamber with live cells was immediately transferred to the microscope stage for direct visualization. At the microscope, the cell culture media was exchanged twice with a $200 \mu \mathrm{l}$ solution of culture media pre-buffered to exactly $\mathrm{pH} 7.00$ with $40 \mathrm{mM}$ HEPES buffer, and images were acquired within the next 10 min (data not shown). Next, in the same culture chamber, the neutral solution was exchanged twice with media pre-buffered to exactly $\mathrm{pH} 4.50$ with $20 \mathrm{mM}$ citrate buffer and images were acquired within the next 10 min. FITC is an acid sensitive dye. The emission spectrum shifts toward shorter wavelengths which are not efficiently captured with standard FITC emission filters ( $<10 \%$ emission captured at $\mathrm{pH} 4.50$ with filter LP505). Thus a "quenching" effect is observed in which only the fluorescence of intracellular dye protected from the low $\mathrm{pH}$ extracellular media is efficiently acquired. Plasma membrane integrity is maintained for greater than $20 \mathrm{~min}$ at low $\mathrm{pH}$. All images were acquired with an inverted Zeiss LSM 510 meta $(63 \times$ objective, N.A. 1.4 , LP505 emission filter $)$ under identical acquisition conditions for each experiment. The yielded results were found to be independent of the pinhole settings. Micrographs were exported to ImageJ (NIH) and processed for presentation using Photoshop (Adobe). Confocal images were acquired such that the Z-dimension was 1 micron.

Plasminogen Binding and Plasmin Activity

Brain extracts ( $n=2-4$ per group) were centrifuged at $100,000 \mathrm{~g}$ and pellets were considered as membrane fractions. Plasmin activity was measured as described before [7]. In brief, pellets were resuspended in Hank's balanced saline solution containing $0.1 \%$ ovalbumin (Sigma) and placed in a 96-multiwell plate in the presence of $2 \mathrm{mM}$ chromogenic substrate S-2251 (Chromogenix) to measure endogenous plasmin activity. Absorbance was measured at $37^{\circ} \mathrm{C}$ and $405 \mathrm{~nm}$ in an ultramicroplate reader every $5 \mathrm{~min}$.

Antibodies, Quantification and ELISA

Monoclonal anti-flotillin-1 (clone 18, Transduction Laboratories), monoclonal anti-cellular prion protein $\left(\operatorname{Prp}^{\mathrm{c}}\right)$ POM-1 (kindly provided by Dr. A. Aguzzi, University of Zurich), monoclonal anti-transferrin receptor (TfR) (Clone CD-71, Santa Cruz Biotechnology Inc.), polyclonal antiC-terminal APP (Sigma), monoclonal anti-N-terminal APP (22C11, Chemicon) and polyclonal anti plasminogen (Biogenesis) were used for Western blot analysis. Monoclonal anti- $\beta$-actin (Abcam) and anti-GAPDH (Biodesign) were used as internal loading controls and for normalization of densitometric analysis of the immunoreactive bands. SDS-PAGE and Western blotting was performed as described [7]. Quantification of immunoreactive bands was carried out by densitometry of the scanned films under conditions of non-saturated signal using the ImageJ software. Murine A $\beta$ ELISA was performed as described [7, 32]. In brief, total brain extracts ( $n=4$ each) and supernatants of primary neurons $(n=4$ for each genotype and time point) were analyzed by a modified sandwich ELISA that detects specifically either $\mathrm{A} \beta_{40}$ (HPR-conjugated $\mathrm{BA} 27$ ) or $\mathrm{A} \beta_{42}$ (HPR-conjugated $\mathrm{BC} 05$ ) (Takeda, Japan) according to the provider's protocol. A $\beta$ was captured with a specific anti-A $\beta$ antibody (BNT77).

\section{Lipid and Sterol Analysis}

Lipids were extracted from membrane pellets and from each sucrose gradient fraction according to the Bligh-Dyer method using chloroform/methanol ( $n=3-4$ per group) [33]. Sphingomyelin, the ganglioside GM1 and phospholipids were determined as described [7]. Briefly, sphingomyelin (SM) was analyzed by thin-layer 
chromatography (TLC), GM1 by slot-blot using cholera toxin subunit B linked to a peroxidase (Sigma) and phospholipids were determined using the Phospholipid B kit (WAKO) according to the manufacture's protocol. Sterols were isolated and analyzed by gas-chromatography/mass spectrometry as described [34]. In addition, total sterols were measured using the Amplex Red Cholesterol Kit (Invitrogen/Molecular Probes) according to the manufacturer's protocol. In brief, the vacuum dried chloroform phase was resuspended in DMSO and applied to the assay in a final dilution of 1:100. The plate was read in a fluorescent micro plate reader using $560 \mathrm{~nm}$ wavelengths for excitation and $590 \mathrm{~nm}$ for emission with a $590 \mathrm{~nm}$ cutoff.

\section{$\alpha$ - and $\beta$-Secretase Activity Assays}

Secretase activities were measured using $\alpha$ - and $\beta$-secretase activity Kits (R\&D systems) as described [35]. In brief, half brains of DHCR24 $4^{-1-}$ and wt mice $(n=4-5$ per group) were homogenized in cell extraction buffer to a final concentration of 1-2 $\mathrm{mg} / \mathrm{ml}$. Homogenates were incubated on ice for $10 \mathrm{~min}$ and centrifuged at $10,000 \mathrm{~g}$ for $1 \mathrm{~min}$. Diluted supernatant, reaction buffer and substrates were added to each well, gently mixed and incubated in the dark at $37^{\circ} \mathrm{C}$ for $1 \mathrm{~h}$. The plate was read in a fluorescent micro plate reader using $355 \mathrm{~nm}$ wavelengths for excitation and $510 \mathrm{~nm}$ for emission with a $495 \mathrm{~nm}$ cutoff.

\section{Reconstitution of BACE in Proteoliposomes} and Proteoliposome Activity Assays

Recombinant BACE was purified from insect cells and reconstituted in large unilamellar vesicles as described previously [36]. The amount of incorporated BACE was determined by densitometry of silver-stained SDS-PAGE gels using a standard curve obtained by loading known amounts of purified BACE in the range of 10-100 ng per lane. Consequently, the specific activity of BACE in each proteoliposome preparation was determined in $0.1 \mathrm{M}$ $\mathrm{NaOAc}, \mathrm{pH} 4.8$ from the slope of the initial linear stage of the enzyme progression curves measured in a timeresolved fluorescence assay (excitation $355 \mathrm{~nm}$, emission $385 \mathrm{~nm}$, measured in $20 \mathrm{~s}$ intervals for $4,000 \mathrm{~s}$ at $37^{\circ} \mathrm{C}$ ) using the FS-1 substrate (Bachem).

\section{Statistical Analyses}

Data were statistically analyzed by a two-tailed $t$-test, with results deemed significant when $P<0.05$. Statistical analyses were not performed in case more than $25 \%$ of the DHCR $24^{-1-}$ data points were below detection level. In all graphs, mean \pm SEM (standard error of the mean) are shown if not otherwise indicated.

\section{Results}

Viability and Neuropathological Status of DHCR24 Mice

DHCR24 knock-out mice (DHCR24 ${ }^{-1-}$ ) were born at lower frequencies than expected, and were smaller in size [9]. The frequency of born DHCR $24^{-1}$ mice from heterozygous matings was increased to an almost normal rate by backcrossing DHCR24 $4^{+/-}$mice to a pure FVB background. To ensure survival of the DHCR24-1- mice, the number of pups was decreased to 3-4 per mating. Under these conditions maternal care was ensured; mice were able to feed (full stomach), and developed normally, although with poorer growth characteristics. Neuropathological examinations of Hematoxylin/Eosin- and Luxol Bluestained cortical sections revealed no obvious abnormalities compared to wt littermates. Since DHCR24/seladin-1 is known to play a role in anti-apoptotic signaling [37-39], we determined apoptotic events in brains of DHCR24 $4^{-1-}$ and wt mice. TUNEL and cleaved caspase- 3 stainings did not reveal any difference between brains of DHCR24 $4^{-1-}$ mice when compared to wt brains (not shown).

Brain Sterol and Lipid Distribution in DHCR24 $4^{-1-}$ Mice

To determine the effects of DHCR24 deficiency on brain sterol metabolism (see Suppl. Fig. 1), we analyzed brains of 3- and 16-week-old DHCR24-1- and wt mice using gaschromatography/mass-spectrometry [34]. Cholesterol, the final product of the Kandutsch-Russel pathway, was virtually absent in DHCR $24^{-1-}$ brains of both ages. Because desmosterol is the last sterol of the Bloch-pathway and its reduction is solely catalyzed by DHCR24, this sterol was greatly accumulating in brains of $\mathrm{DHCR} 24^{-1-}$ mice (Fig. 1a). Quantitatively, desmosterol levels in 3-week-old DHCR $24^{-1-}$ mice reached about $50 \%$ of the levels of cholesterol in wt mouse brains, while further desmosterol buildup in brains of 16 -week-old DHCR $24^{-1-}$ mice resulted in desmosterol concentration comparable to that of cholesterol in aged-matched wt mice (Fig. 1a, Table 1). Detailed analysis of brain sterol synthesis revealed that besides cholesterol, components of the Kandutsch-Russel pathway such as lathosterol were virtually absent in DHCR24 $4^{-1-}$ mice of either age-group. In addition, the brain specific catabolic product of cholesterol, 24S-hydroxycholesterol (24S-OH-chol), was significantly reduced with DHCR24 deficiency (Table 1). The total amount of sterols in 3-weekold DHCR24 $4^{-1-}$ brains was reduced by $\sim 47 \%$, while no significant difference in total sterols was detected in 16week-old DHCR24 $4^{-1-}$ brains, due to the age-dependent accumulation of desmosterol. The amount of brain 

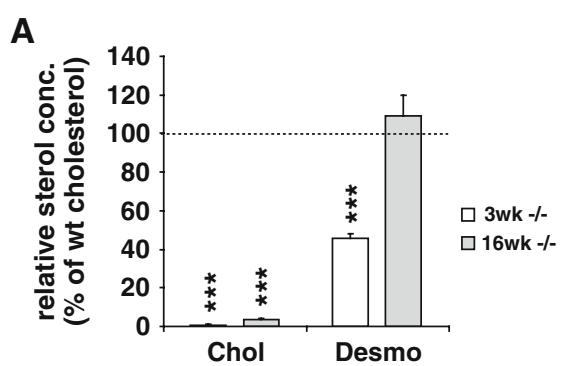

C

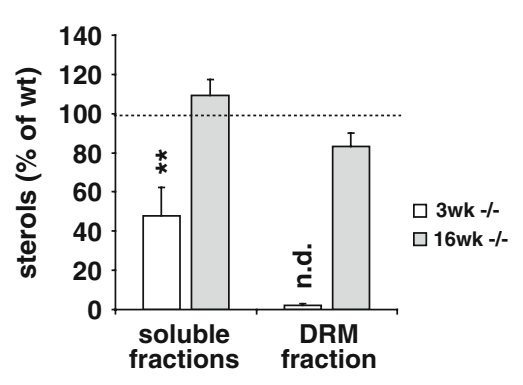

Fig. 1 Sterol, lipid and protein distribution in brains of 3- and 16week-old DHCR $24^{-1-}$ mice. a Brain sterols were determined by GS/ MS. Cholesterol was virtually absent in brains of 3-week-old DHCR $24^{-1-}$ mice (3 weeks $-/-$ ), while desmosterol accumulated and accounted for $\sim 50 \%$ of cholesterol compared to wt controls (3 weeks $+/+$, set as $100 \%$ ). Brains of 16 -week-old DHCR $24^{-/-}$ mice were essentially cholesterol-free (16 weeks -/-), whereas desmosterol accumulated to levels that are comparable to those of cholesterol in aged-matched wt controls (16 weeks $+/+$ ). b Phospholipid concentrations in total brain extracts were similar in both genotypes and age-groups. c Soluble fractions were separated from insoluble DRM fractions by sucrose gradient fractionation. Total sterols were substantially reduced in soluble factions of 3-week-old
B

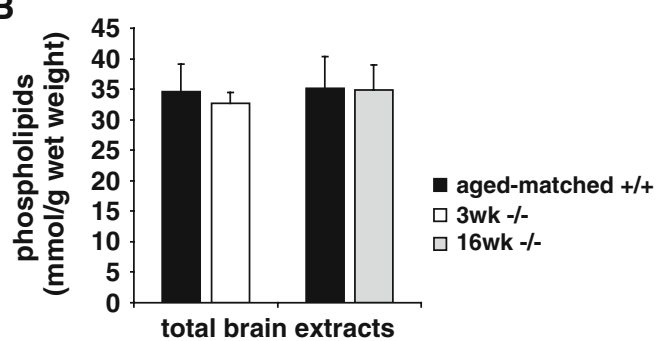

D

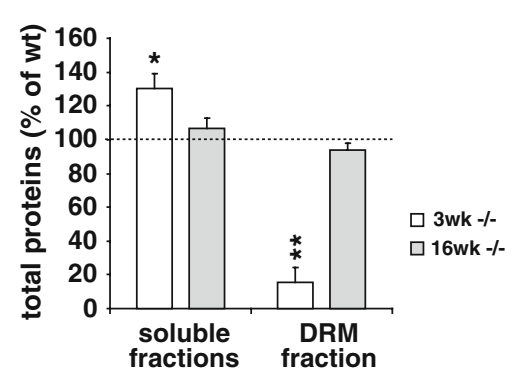

DHCR $24^{-1-}$ mice compared to the corresponding values of their wt littermates (set as 100\%), while sterols were below detection level in DRM fractions of these mice (n.d., not detectable). Sterol levels were similar in soluble fractions of 16 -week-old DHCR $24^{-1-}$ and wt mice, and the amount of desmosterol recruited to DRM fractions of 16week-old DHCR24 $4^{-1-}$ mice was not different from the values of aged-matched controls (set as $100 \%$ ). d The amount of total proteins was increased in soluble and decreased in DRM fractions of 3-weekold DHCR $24^{-1-}$ mice, indicating a replacement of raft proteins to non-raft fractions. This replacement was abolished in 16-week-old DHCR $24^{-1-}$ mice when compared to aged-matched control (set as $100 \%)(* P<0.04, * * P<0.01, * * * P<0.001)$

Table 1 Brain sterol concentrations

\begin{tabular}{llcccc}
\hline Age & & Cholesterol $(\mu \mathrm{g} / \mathrm{mg})$ & Desmosterol $(\mu \mathrm{g} / \mathrm{mg})$ & Lathosterol $(\mathrm{ng} / \mathrm{mg})$ & $24 S$-OH-Chol $(\mathrm{ng} / \mathrm{mg})$ \\
\hline 3 Weeks & $+/+$ & $60 \pm 7$ & $0.6 \pm 0.08$ & $391 \pm 87$ & $340 \pm 53$ \\
& $-1-$ & $2.5 \pm 0.05^{*}$ & $27 \pm 0.05^{*}$ & $25 \pm 1^{*}$ & $15 \pm 7^{*}$ \\
\multirow{3}{*}{ W Weeks } & $+/+$ & $88 \pm 7$ & $0.5 \pm 0.02$ & $140 \pm 14$ & $157 \pm 7.4$ \\
& $-/-$ & $3 \pm 0.3^{*}$ & $97 \pm 11^{*}$ & $1 \pm 0.4^{*}$ & $10 \pm 2^{*}$ \\
\hline
\end{tabular}

Concentrations of cholesterol and desmosterol (in $\mu \mathrm{g} / \mathrm{mg}$ wet weight; mean $\pm \mathrm{SD}$ ), and lathosterol and $24 S$-OH-cholesterol (in $\mathrm{ng} / \mathrm{mg}$ wet weight; mean $\pm \mathrm{SD})$ in brains of $\mathrm{wt}(+/+)$ and DHCR $24^{-l-}(-/-)$ mice of either age-group. Sterols were measured by GC/MS

$* P<0.05$ versus aged-matched controls

phospholipids was unchanged between the DHCR24 $4^{-1-}$ and wt brains of either age-group (Fig. 1b).

Given the fundamental role of cholesterol in DRM composition [7, 25], we studied the effects of chronic cholesterol deficiency on DRM protein and lipid composition in vivo by preparing DRMs from 3- to 16-week-old DHCR $24^{-l-}$ and wt brains. Sterol analysis revealed a major reduction of total sterols in soluble fractions 8-10 of 3-week-old DHCR24 $4^{-1-}$ brains $(47.8 \pm 14.3 \%, P=$ 0.0091 , Fig. 1c), and sterols were even below detection level in DRM fractions (4-6) of these mice. In contrast to the 3-week-old mice, sterol levels in soluble fractions 8-10 of 16-week-old DHCR $24^{-1-}$ mice were comparable to that of aged-matched wt mice, and a substantial amount of sterols was detected in DRM fractions of 16-week-old DHCR $24^{-/-}$mice $(83.2 \pm 6.2 \%$ of wt, Fig. 1c), revealing a recruitment of desmosterol to DRM fractions of 16-weekold DHCR $24^{-1-}$ mice.

Determination of the total amount of proteins in soluble and DRM fractions of 3- and 16-week-old DHCR24-1mice revealed that in 3 -week-old DHCR24 ${ }^{-1-}$ mice proteins were significantly reduced in DRM fractions 
$(15.3 \pm 8.7 \%$ of wt, $P=0.0044$, Fig. 1d), while no significant difference was detected in DRM fractions of 16-week-old DHCR $24^{-/-}$mice, when compared to agedmatched wt control levels. Unlike the amount of sterols, the detected amount of proteins in soluble fractions of 3-weekold DHCR $24^{-1-}$ mice was higher $(130 \pm 8.6 \%, P=0.04)$ compared to aged matched wt mice, possibly indicating a displacement of proteins from DRM to soluble fractions in 3-week-old DHCR $24^{-1-}$ mice. This displacement was abolished in 16-week-old DHCR24 ${ }^{-l-}$ mice, where the amount of proteins detected in soluble fractions was similar to that of aged-matched wt mice (Fig. 1d).

Subcellular Protein and Lipid Distribution in Brains of DHCR24 ${ }^{-/-}$Mice

Analysis of the flotation profiles of the raft-specific protein $\operatorname{Prp}^{c}$ (cellular prion protein) revealed a substantial percentage of this protein in DRM fractions of 3-week-old wt brains $(47.6 \pm 4.6 \%)$, while dramatically less $\operatorname{Prp}^{c}$ was detected in these fractions of 3-week-old DHCR24 ${ }^{-1-}$ brains $(3.5 \pm 1.2 \%$, Fig. 2a). Altered DRM formation in 3-week-old DHCR24 ${ }^{-1-}$ brains was further confirmed determining the subcellular distribution of the raft marker flotillin-1 that was virtually absent from DRM fraction of 3-week-old.

DHCR $24^{-1-}$ brains, while $42.8 \pm 3.9 \%$ of flotillin- 1 was present in these fractions of wt mice (Fig. 2b). In addition, the $\beta$-secretase BACE that is known to reside within lipid rafts, was substantially reduced in DRM fractions of 3-week-old DHCR24 $4^{-l-}$ brains $(3.7 \pm 1.6 \%)$, while an evident percentage of BACE was detected in these fractions of aged-matched wt mice $(43.7 \pm 0.4 \%$, Fig. $2 c)$. However, the absolute levels of $\operatorname{Prp}^{\mathrm{c}}$, flotillin-1 and BACE were not altered in total brain homogenates of 3-week-old DHCR $24^{-1-}$ and wt mice (see Suppl. Fig. 2c). The non-raft protein APP remained in the heavy fractions to a comparable extent in brains of 3-week-old DHCR2 $4^{-1-}$ and wt mice (Fig. 2d). Lipid analysis of sucrose gradient fractions of 3-week-old DHCR24 ${ }^{-l-}$ mice revealed major changes in the distribution of SM and the ganglioside GM1 in the DHCR24 ${ }^{-l-}$ compared to wt brains (Suppl. Fig. 2a, b). While in control brains $37.6 \pm 6.5 \%$ of $\mathrm{SM}$ and $71.8 \pm 5.5 \%$ of GM1 were found in DRM fractions $4-6$, only $6 \pm 3.0 \%$ of SM and $2.4 \pm 1.2 \%$ of GM1 were present in DRM fractions of DHCR2 $4^{-1-}$ brains (Suppl. Fig. 2a, b).

In contrast, no significant differences in the subcellular distribution of raft-proteins were detected between 16-weekold DHCR24 ${ }^{-1-}$ and wt mice: distinct proportions of $\operatorname{Prp}^{\mathrm{c}}$ $(45.8 \pm 2.1 \%$, Fig. 3a), flotillin-1 $(48.1 \pm 2.1 \%$, Fig. 3b) and BACE $(44.6 \pm 6.6 \%$, Fig. $3 \mathrm{c})$ were detected in DRM fractions of 16-week-old DHCR2 $4^{-1-}$ brains, comparable to
A
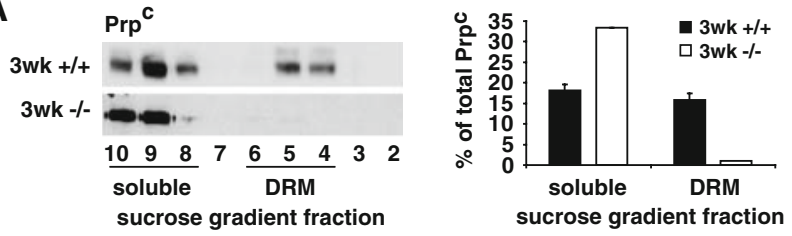

B
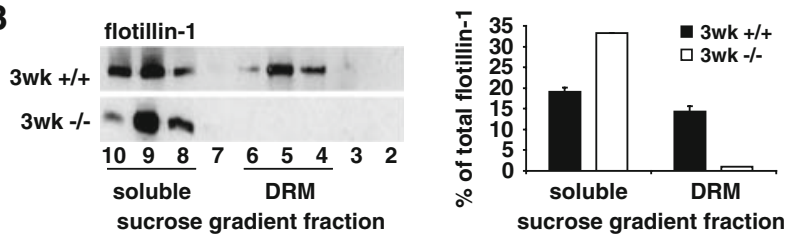

C
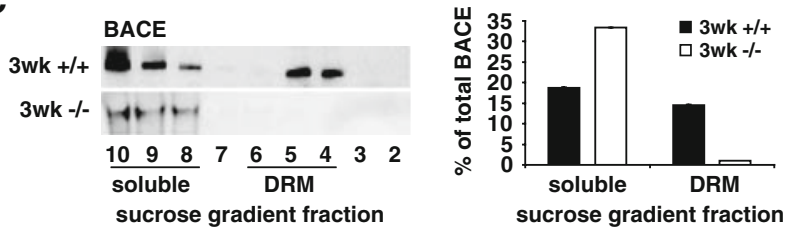

D
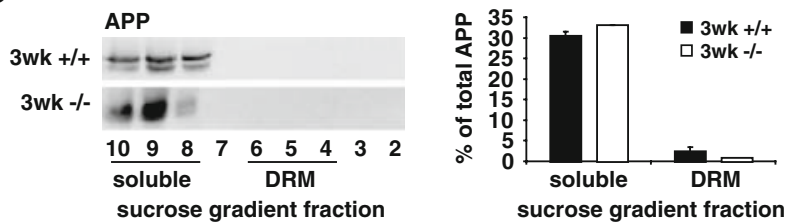

Fig. 2 Effects of sterol alterations on membrane organization of 3-week-old DHCR24-1- mice. Total extracts from 3-week-old mouse brains were separated in a sucrose gradient. Fractions were collected and numbered from the lightest to the heaviest (2-10). Representative Western blots of the flotation profiles of the raft proteins $\operatorname{Prp}^{c}(\mathbf{a})$, flotillin-1 (b) and BACE (c) show a general displacement of these proteins from DRM to soluble fractions of 3-week-old DHCR24-1mice ( 3 weeks $-/-$ ), when compared to wt controls ( 3 weeks $+/+$ ), while the cellular distribution of APP (d), a non-raft protein, was not altered between the two genotypes. Graphs on the right show the distribution of the four proteins in soluble (8-10) and DRM (4-6) fractions as average percentage of the total amount of the respective proteins along the entire gradient

those in DRM fractions of wt brains $(48.1 \pm 1.7$ and $42.8 \pm 7.3$ and $36 \pm 1.1 \%$, respectively, Fig. $3 a-c)$. Like in 3-week-old DHCR24 ${ }^{-1-}$ mice, the subcellular distribution of the mainly non-raft protein APP in soluble fractions was not altered between the two genotypes in the 16-week-old brains (Fig. 3d).

Plasminogen Binding and Plasmin Activity in DHCR24 ${ }^{-1-}$ Mice

To evaluate the functional consequences of the observed disturbances in DRM composition in 3-week-old DHCR $24^{-1-}$ mice, we analyzed plasmin activity in plasma membranes of 3- and 16-week-old DHCR $24^{-1-}$ mouse brains. Plasmin activity is regulated by plasminogen 


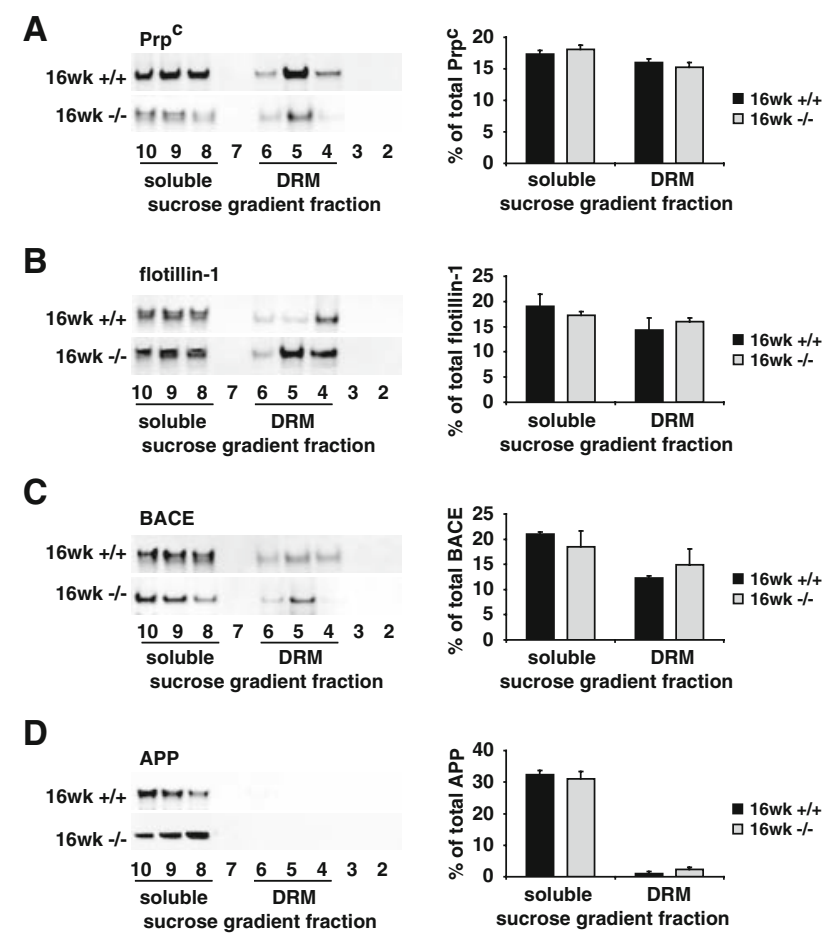

Fig. 3 Effects of sterol alterations on membrane organization of 16week-old DHCR $24^{-1-}$ mice. Total extracts from 16-week-old mouse brains were separated in a sucrose gradient. Fractions were collected and numbered from the lightest to the heaviest (2-10). Compared to 3 -week-old DHCR $24^{-1-}$ mice, raft-protein levels in DRM fractions of 16-week-old DHCR24 ${ }^{-1-}$ mice $(16$ weeks $-/-$ ) were restored to $\mathrm{wt}$ (16 weeks $+/+$ ) level. Distinct proportions of $\operatorname{Prp}^{\mathrm{c}}(\mathbf{a})$, flotillin-1 (b) and BACE (c) were determined in DRM fractions of 16-week-old DHCR $24^{-1-}$ mice. d APP distribution was similar in 16-week-old DHCR $24^{-1-}$ and wt mice. Graphs on the right show the distribution of the four proteins in soluble (8-10) and DRM (4-6) fractions as average percentage of the total amount of the respective proteins along the entire gradient

activators, plasminogen activator inhibitors and plasmin inhibitors [40]. In addition, plasmin generation is dependent on the binding of plasminogen to the plasma membrane [41]. Experimental data point to DRMs as the sites where the plasminogen binding and activation take place. Moreover, plasminogen-binding molecules are enriched in rafts of neurons [42], and plasmin is almost exclusively present in these neuronal microdomains [43]. We measured plasmin enzymatic activity using the chromogenic substrate S-2251 specific for this protease. Plasmin activity in isolated membranes of 3-week-old DHCR $24^{-1-}$ brains was dramatically reduced (Fig. 4a). Accordingly, the amount of endogenous plasminogen bound to the membrane was diminished in 3-week-old DHCR $24^{-l-}$ mice, while the endogenous levels of total plasminogen were similar to that in aged-matched wt mice (Fig. 4b), suggesting an impaired binding capacity for plasminogen to the membrane. Conversely, plasmin activity was restored in brains of 16-week-old DHCR24 $4^{-/-}$ mice (Fig. 4c) and no difference was detected in the amount of membrane-bound plasminogen between 16-week-old DHCR $24^{-1-}$ and aged-matched wt mice (Fig. 4d).

\section{APP Processing and $\mathrm{A} \beta$ Generation in DHCR $24^{-/-}$} Mice

Next, we studied APP processing as another example of membrane-dependent proteolysis and raft-related cellular event to evaluate the effects of chronic cholesterol deficiency and possible replacement by desmosterol on functional level in vivo. In 3- and 16-week-old mice, levels of cellular full-length APP were similar in brains of DHCR $24^{-1-}$ and wt mice, and there was no significant alteration in membrane fractions of full-length APP (Fig. 5a, b). Analysis of APP cleavage products revealed that the amount of $\alpha$-CTF was not significantly different in the 3-week-old DHCR $24^{-1-}$ brains $(124 \pm 9.8 \%$, Fig. 5a, c), whereas the $\beta$-CTF was significantly lower $(54 \pm 5.6 \%$, $P=0.009$, Fig. 5a, c), when compared to wt mice. However, this difference was abolished in brains of 16-week-old DHCR $24^{-1-}$ mice, which exhibited similar levels of $\beta$-CTF when compared to aged-matched wt mice (Fig. 5b, c). In addition, $\mathrm{A} \beta_{40}$ levels were significantly lower in brains of 3 -week-old DHCR24 ${ }^{-1-}$ mice $(42.9 \pm 4.3 \%, P=0.0004$, Fig. 5d). Brain $\mathrm{A} \beta_{42}$ levels were below detection limits in either genotype in 3-week-old mice. On the contrary, $\mathrm{A} \beta_{40}$ concentrations were similar between 16-week-old DHCR $24^{-1-}$ and wt mice (Fig. 5d). Moreover, in 16-weekold mice, $\mathrm{A} \beta_{42}$ was detectable in either genotype, and did not differ between DHCR $24^{-1-}$ and wt mice (Fig. 5d).

These data provide the evidence that APP processing and $\mathrm{A} \beta$ generation are strongly influenced by cholesterol deficiency due to DHCR24 disruption in vivo, whereas high levels of desmosterol in 16-week-old DHCR24 $4^{-1-}$ mice seem to rescue these deficits. To evaluate whether the changes in APP processing and $\mathrm{A} \beta$ generation in 3-weekold DHCR $24^{-/-}$brains were due to altered activities of involved secretases, we determined $\alpha$ -,$\beta$ - and $\gamma$-secretase activity in brain homogenates of DHCR $24^{-1-}$ and wt mice. $\beta$-secretase activity was significant reduced in 3-week-old DHCR $24^{-1-}$ brains $(71.4 \pm 2.4 \%, P=0.0257$, Fig. 5 e $)$. In addition there was a moderate reduction in $\gamma$-secretase activity in brains of 3 -week-old DHCR24 ${ }^{-1-}$ mice (90.2 $\pm 5 \%, P=0.039$, Fig. 5e). Brain activity levels of $\alpha$-secretase were unchanged in 3 -week-old DHCR24 ${ }^{-1-}$ mice when compared to age-matched wt controls. In contrast, brain activities of all three secretases were unchanged in 16-week-old DHCR24 $4^{-1-}$ mice, suggesting that high concentrations of desmosterol and integration of desmosterol in the membrane restores full $\beta$-and $\gamma$-secretase activity. 
A

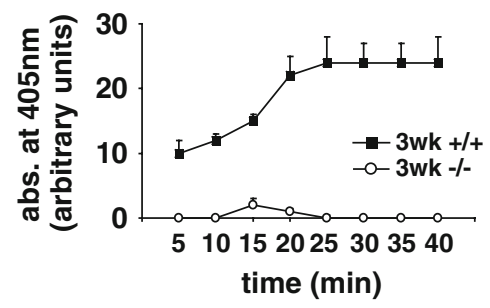

C

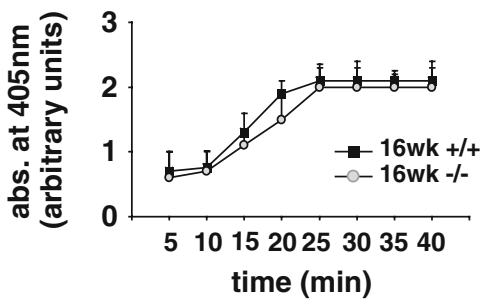

B

3 week-old mice:

brain homogenates

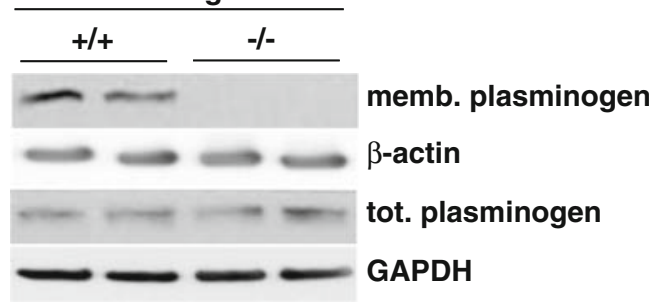

D

16 week-old mice:

brain homogenates

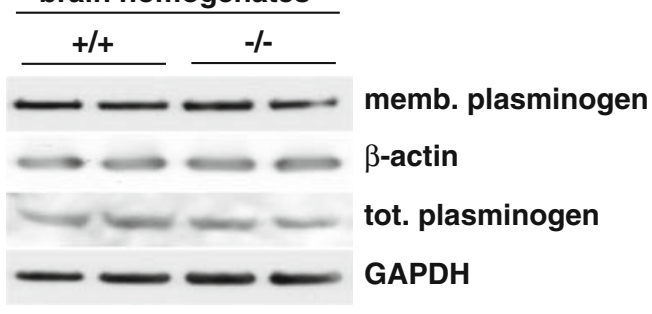

DHCR24 ${ }^{-1-}$ brains, while levels of total cellular plasminogen (tot. plasminogen) were not altered between 3 -week-old DHCR24 ${ }^{-1-}$ and wt brains. c In 16-week-old DHCR24 $4^{-1-}$ mice (16 weeks -/-), plasmin activity was restored to wt levels $(16$ weeks $+/+)$. d Plasminogen levels bound to membranes of 16 -week-old DHCR24 ${ }^{-1-}$ mice were comparable to aged-matched wt mice and no difference was observed in total plasminogen levels between the two genotypes. GAPDH is shown as a loading control for total extracts, $\beta$-actin for the membrane preparations

cultures (Fig. 6e), while both $\mathrm{A} \beta$ species were present to comparable levels in neurons of both genotypes cultured for 8-10 div (Fig. 6f). These data clearly indicate that desmosterol, insofar it is abundant enough, can rescue the membranerelated deficits caused by chronic cholesterol deficiency.

Specific Activity of BACE Reconstituted in Proteoliposomes

To rule out that factors other than high desmosterol concentration are responsible for the observed rescue effects in APP processing, we investigated the specific activity of BACE reconstituted in large unilammelar vesicles formulated as sterol free, or including cholesterol, desmosterol, or 7-ketocholesterol.

BACE was reconstituted in vesicles composed of palmitoyloleoyl phosphatidylcholine (POPC), brain phosphatidylethanolamine $(\mathrm{PE})$, and brain $\mathrm{SM}$ in a ratio of $50: 20: 30 \mathrm{~mol} / \mathrm{mol}$ (approximately the same ratios in $\mathrm{w} / \mathrm{w}$ ) without a sterol component, and in vesicles containing POPC:brainPE:brainSM:cholesterol in a ratio of 50:20:10: $20 \mathrm{~mol} / \mathrm{mol}$ ( 56:22:11:11 w/w), POPC:brainPE:brainSM: desmosterol 50:20:10:20 mol/mol ( 56:22:11:11 w/w) and 
A

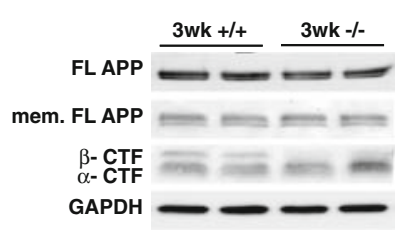

D

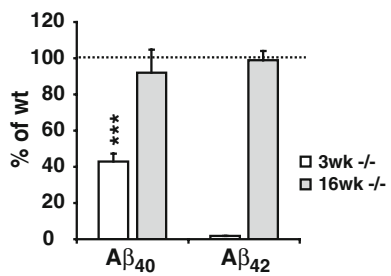

B

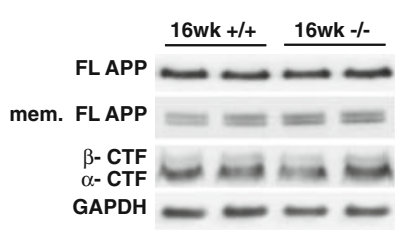

C

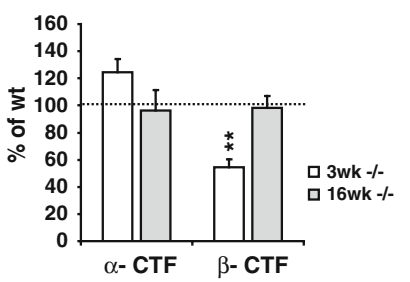

\section{E}

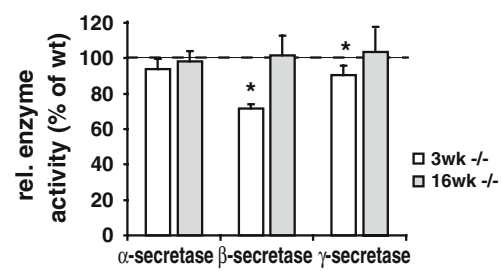

Fig. 5 APP processing, A $\beta$ generation and secretase activity in brains of DHCR $24^{-1-}$ mice. Hemi brains of mice were homogenized in a Tris-buffer containing 2\% SDS (total extracts) or in a MES buffer lacking detergent (for membrane preparations). Total extracts and membrane fractions were subjected to Western blot analysis. a Cellular and membrane (mem.) level of full length (FL) APP were unchanged between the two genotypes, whereas the levels of CTFs were altered in 3-week-old DHCR24 $4^{-1-}(3$ weeks $-/-)$ mouse brains. b In 16 -week-old DHCR $24^{-1-}$ mice $(16$ weeks $-/-$ ) cellular and membrane FL APP and CTF levels were not different from wt controls (16 weeks $+/+$ ). GAPDH was used as internal loading control for total extracts. c Quantification of the CTFs revealed that $\alpha$-CTFs were not altered in DHCR $24^{-1-}$ mice of either age-group, whereas $\beta$-CTFs were significantly reduced in 3 -week-old DHCR $24^{-1-}$ brains, when compared to corresponding levels of agematched wt mice ( 3 weeks $+/+$, set as $100 \%$ ), while this reduction was abolished in 16-week-old DHCR24 $4^{-1-}$ brains. d Hemi brains

POPC:brainPE:brainSM:7-ketocholesterol 50:20:10:20 mol/ $\operatorname{mol}(\sim 56: 22: 11: 11 \mathrm{w} / \mathrm{w})$.

Relative to cholesterol containing vesicles in which BACE activity was set as $100 \%$, sterol-free proteoliposomes displayed a specific activity of only $48 \pm 2.8 \%$. However, desmosterol caused an effect comparable to cholesterol, increasing the specific activity of BACE to $80 \pm 10.4 \%$ (Fig. 7a).

In order to rule out that the increased activity primarily depends on decreasing amounts of SM rather than on the identity of the included sterol, BACE was reconstituted in vesicles with 7-ketocholesterol. This sterol was studied in model membranes and was found to differ from cholesterol in a number of important parameters, for example, 7-ketocholesterol is less effective in forming ordered lipid domains, and was shown to differentially modulate membrane properties involved in protein-membrane association and function [44]. Compared to cholesterol-free proteoliposomes, only a minor effect was observed with 7-ketocholesterol $(56 \pm 5.8 \%$, Fig. 7a). Figure $7 \mathrm{~b}$ shows the range of linear correlation between BACE activity and the slope of the initial stage of progression curve.

were homogenized in PBS and subjected to murine $\mathrm{A} \beta$ ELISA analyses as described in "Materials and methods". In comparison to age-matched controls (set as $100 \%$ ), $\mathrm{A} \beta_{40}$ levels were significantly diminished in 3 -week-old DHCR $24^{-1-}$ brains, while these levels were normal in 16-week-old mice. A $\beta_{42}$ peptides were below detection level in brains of 3 -week-old DHCR $24^{-1-}$ and wt mice (n.d., not detectable). In 16-week-old mice $\mathrm{A} \beta_{42}$ levels were unchanged compared to aged-matched controls. e Hemi brains were homogenized and subjected to secretase activity assays. Proteolytic activity of $\alpha$-secretase was unchanged in DHCR $24^{-/-}$brains of either age-group. $\beta$ - and $\gamma$-secretase activity were significantly reduced in 3 -week-old DHCR $24^{-1-}$ brains, while full proteolytic activity of both secretases was observed in 16-week-old DHCR24 ${ }^{-1-}$ mice compared to their age-matched controls. Activity levels of secretases in aged-matched wt controls were set as $100 \% \quad(* P<0.04$, ** $P<0.01$, *** $P<0.0005)$

\section{Binding and Internalization of GM1 in DHCR24 ${ }^{-1-}$ Derived Primary Cortical Neurons}

Our studies of APP processing and $\mathrm{A} \beta$ generation, and of BACE activity in desmosterol-containing proteoliposomes suggest that desmosterol can functionally replace cholesterol in DHCR $24^{-1-}$ mice. To investigate using intact live cells the functional replacement by desmosterol of cholesterol, we monitored the plasma membrane distribution and the internalization of the raft-associated lipid GM1 in primary cortical neurons of wt and DHCR $24^{-1-}$ mice. GM1 is a glycosylated sphingolipid enriched in membrane microdomains and in membranes within caveole. Biosynthesis, endocytosis and membrane trafficking of GM1 are highly sensitive to acute cholesterol depletion [45]. The bacterial toxin subunit $\beta$ from vibrio cholera (Cholera toxin $\beta$ ) binds GM1 with high specificity [46]. When fluorescently modified with FITC (FITC-Ctx $\beta$ ), it is routinely employed either as a stain to visualize the subcellular localization of GM1, or as an extracellular ligand to visualize GM1 endocytosis events and vesicular trafficking [45]. We visualized primary cortical neurons derived from 
A

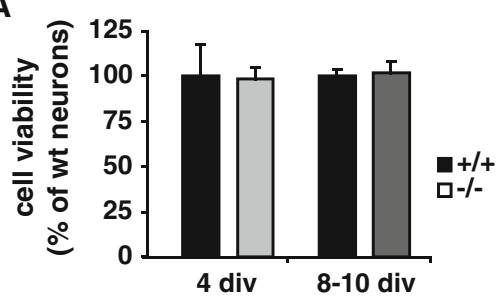

C

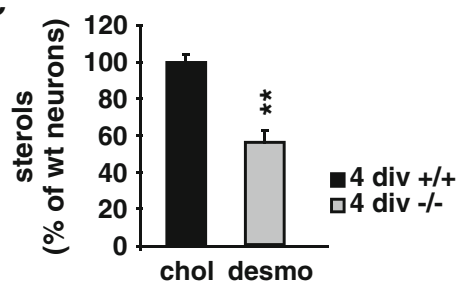

$\mathbf{E}$

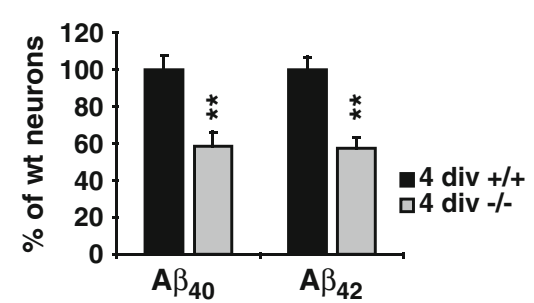

Fig. 6 Sterol distribution and $\mathrm{A} \beta$ generation in primary neurons of DHCR $24^{-1-}$ mice. Primary neurons were prepared from DHCR $24^{-1-}$ and wt mice and cultured in cholesterol- and serum-free medium. a Cell viability of primary neurons in culture for up to 10 days in vitro (div) was not different between DHCR24 ${ }^{-1-}(4 / 8-10 \mathrm{div}-/-)$ and wt (4/8-10 div +/+) neurons. b Sterol levels of primary neurons derived from DHCR24 $4^{-1-}$ mice gradually increased with age reaching wt levels (set as $100 \%$ ) between 8 and 10 div. c After 4 div, the levels of desmosterol in DHCR24 $4^{-/-}$neurons were approximately half of that

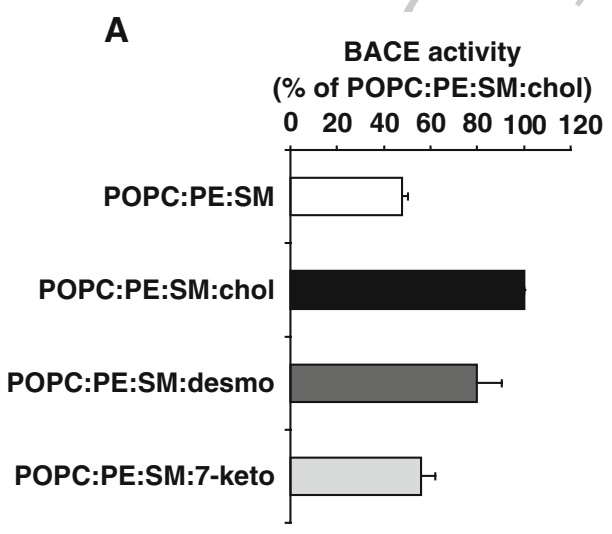

Fig. 7 Specific activity of BACE reconstituted in proteoliposomes. a BACE was reconstituted in vesicles composed of POPC:brainPE:brainSM 50:20:30 mol/mol, POPC:brainPE:brainSM:cholesterol 50:20:10:20 mol/mol, POPC:brainPE:brainSM:desmosterol 50:20:10: $20 \mathrm{~mol} / \mathrm{mol}$ and POPC:brainPE:brainSM:7-ketocholesterol 50:20:10: $20 \mathrm{~mol} / \mathrm{mol}$. The specific activity of BACE in each proteoliposome preparation was determined from the slope of the initial linear stage of the enzyme progression curves measured in a time-resolved

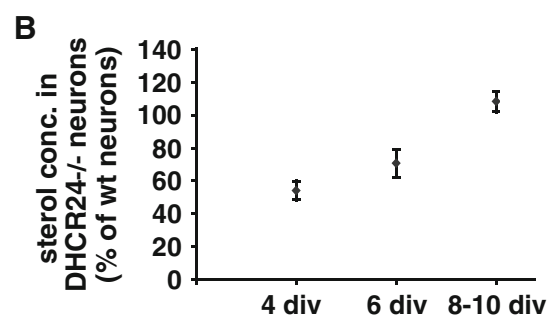

D

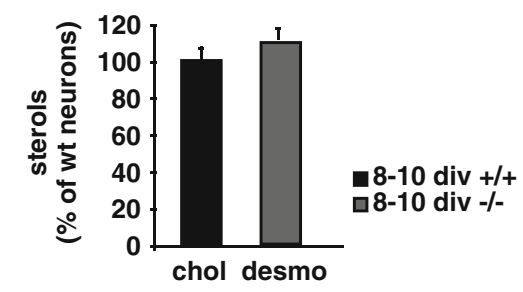

$\mathbf{F}$

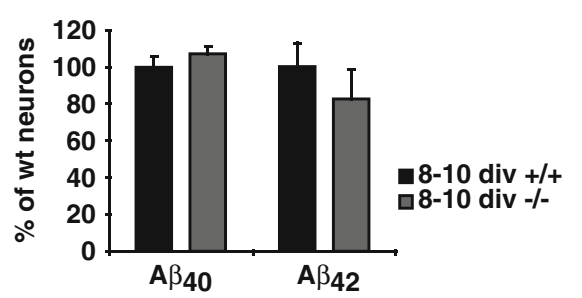

of cholesterol in wt controls (set as 100\%). d After 8-10 div, desmosterol concentrations in neurons prepared from DHCR $24^{-1-}$ mice were similar to that of cholesterol in wt control cultures (set as $100 \%$ ). e Secreted $\mathrm{A} \beta_{40}$ and $\mathrm{A} \beta_{42}$ in the supernatant of the DHCR $24^{-1-}$ cultures revealed a significant reduction of both peptides compared to control cultures (set as 100\%) after 4-5 div. f The difference in $\mathrm{A} \beta_{40}$ and $\mathrm{A} \beta_{42}$ levels between $\mathrm{DHCR} 24^{-1-}$ and wt neurons (set as $100 \%$ ) detected in 4-5 div-cultures was abolished after $8-10 \operatorname{div}(* * P<0.003)$

B

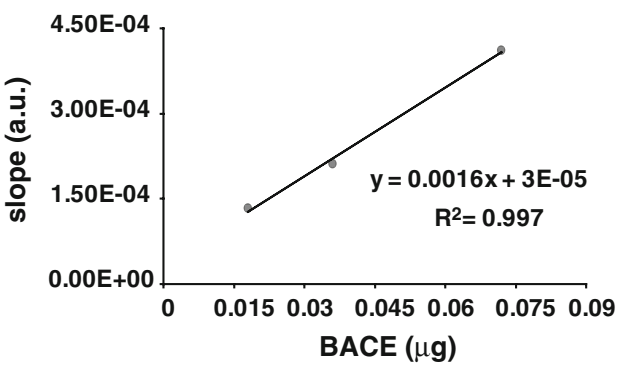

fluorescence assay. Specific BACE activity in each particular mixture is expressed in percentage relative to the specific activity of BACE in cholesterol containing proteoliposomes. Incorporation of desmosterol caused an effect comparable to that of cholesterol, markedly increasing the specific activity of BACE, while incorporation of 7-ketocholesterol, a membrane inactive sterol, showed only a minor effect. b Range of linear correlation between BACE activity and the slope (in arbitrary units, a.u.) of the initial stage of progression curve 


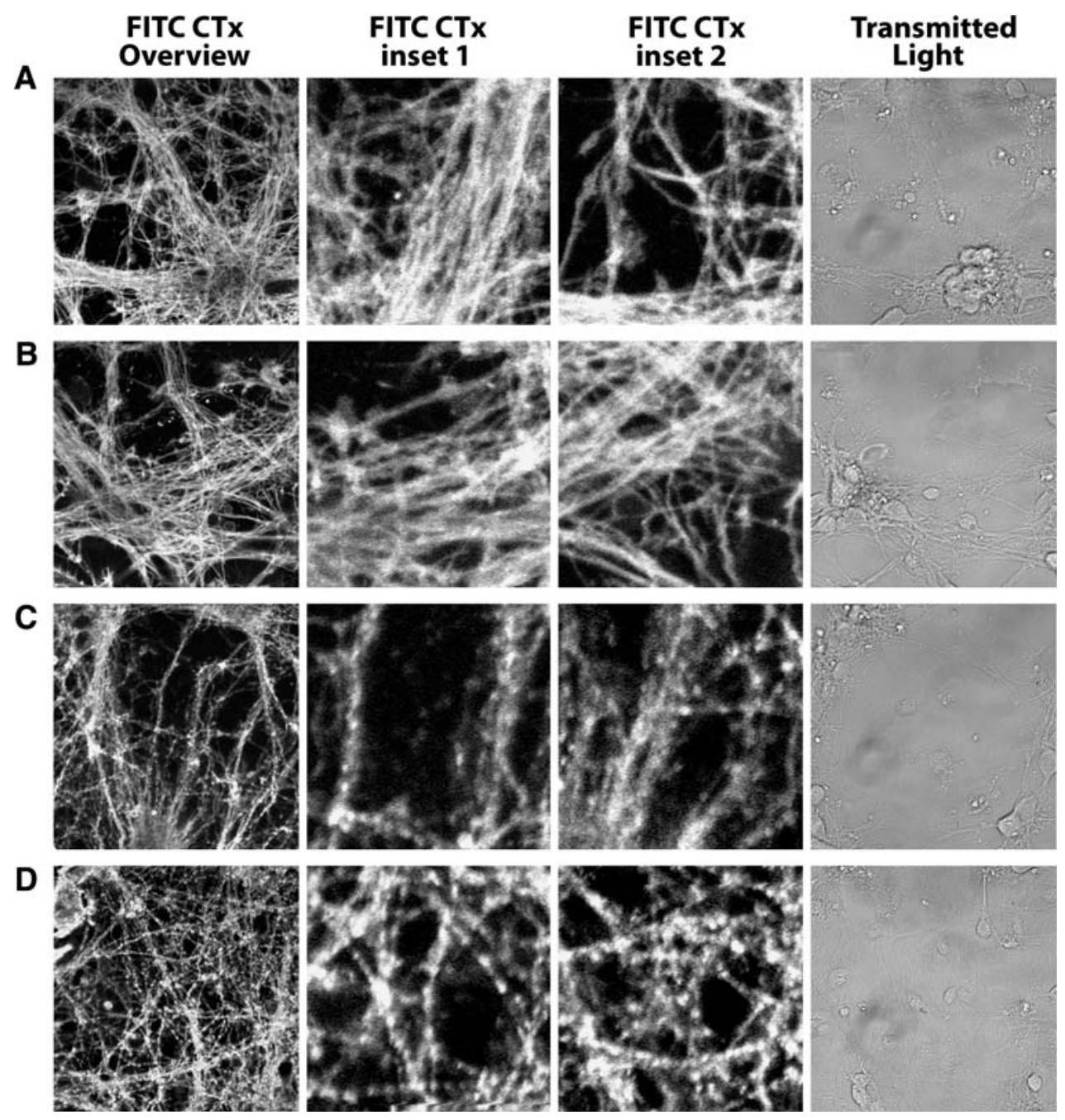

Fig. 8 Binding and internalization of GM1 in live DHCR24 $4^{-/-}$ derived primary cortical neurons. Confocal micrographs of live (a) wt and (b) DHCR24 $4^{-1-}$ derived primary cortical neurons pulsed for 2 min with FITC-Ctx $\beta$ are shown, including four panels for each: FITC CTx overview image, FITC CTx inset 1, FITC CTx inset 2, Transmitted Light. The FITC-Ctx $\beta$ shows a pattern similar to the neuron plasma membrane pattern (compare FITC CTx and transmitted light), indicating FITC-Ctx $\beta$ is plasma membrane associated in wt and DHCR $24^{-1-}$ live neurons at 6 div. The pool of receptor GM1 is similar in wt and DHCR $24^{-1-}$ live neurons at 6 div since fluorescence

DHCR $24^{-1-}$ mice after 6 div when desmosterol levels are comparable to the cholesterol levels in neurons derived from wt mice. Confocal micrographs of live primary cortical neurons of wt and DHCR2 $4^{-1-}$ mice show a comparable plasma membrane staining of FITC-Ctx $\beta$ (Fig. 8a, b), when they are pulsed for 2 min with culture media containing the ligand, and then immediately visualized. This indicates that the surface accessible pools of plasma membrane-exposed GM1 are similar. Next, we visualized the internalization of plasma membrane bound FITC-Ctx $\beta$ in live neurons. To distinguish the intracellular FITC-Ctx $\beta$ from that which is cell surface-associated, we intensity of FITC-Ctx $\beta$ is comparable (compare FITC CTx intensity of $\mathbf{a}-\mathbf{b})$. c Wt and d DHCR $24^{-1-}$ derived primary cortical neuron micrographs of intracellular FITC-Ctx $\beta$ selectively visualized in live cells using low $\mathrm{pH}$ media to shift the fluorescence spectrum of FITC. Images acquired at low $\mathrm{pH}$ show the FITC-Ctx $\beta$ is internalized (compare FITC CTx and transmitted light; compare FITC Ctx of $\mathbf{a}$ and $\mathbf{b}$ to $\mathbf{c}$ and $\mathbf{d})$. Levels of internalized GM1 are comparable (compare FITC CTx intensity of $\mathbf{c}-\mathbf{d}$ ). Scale bar is 10 microns of FITC CTx overview image, insets are $\times 4$ magnification of FITC CTx overview

took advantage of the acid sensitivity of FITC. Following a 2 min pulse with culture media containing the ligand and $30 \mathrm{~min}$ chase in which cells were cultured without ligand, live cells were bathed in low-pH media to "quench" the fluorescent signal of extracellular dye. Micrographs acquired within the first 5-10 $\mathrm{min}$ of exposure to low-pH media reveal that the intracellular fraction of FITC-Ctx $\beta$ in live neurons derived of $\mathrm{wt}$ and DHCR $24^{-1-}$ mice are similar (Fig. 8c, d).

These data indicate that the steady state distribution and the internalization of plasma membrane GM1 are comparable when the membrane sterol desmosterol replaces 
cholesterol. In summary, our data suggest that desmosterol functionally replaces cholesterol in DHCR $24^{-/-}$mice.

\section{Discussion}

The results of this study show that desmosterol-when it is present in the DHCR $24^{-1-}$ mouse brain as abundantly as naturally occurring cholesterol-replaced cholesterol in DRMs and restored membrane-related functions including membrane receptor ligand binding and activation, and regulation of membrane protein proteolytic activity.

In DHCR $24^{-/-}$mice, the conversion of desmosterol to cholesterol is abolished, causing an accumulation of desmosterol with age over time. Whereas in 3-week-old DHCR $24^{-/-}$mice brain desmosterol concentrations were only half of the cholesterol content in wt brains, desmosterol accumulated in 16-week-old DHCR $24^{-1-}$ mouse brains to a concentration similar to that of cholesterol in control brains. A possible explanation for the decelerated production and accumulation of desmosterol in 3-week-old DHCR24 $4^{-1-}$ mouse brains compared to cholesterol in control brains might be an inhibiting effect of accumulating sterol intermediates of the Bloch-pathway on the HMG-coA-reductase [47-49], a rate-limiting enzyme in the cholesterol biosynthesis pathway. This inhibiting effect is likely to be narrowed in adulthood when brain cholesterol synthesis is quite low compared to developmental stages [8].

Brain cholesterol deficiency and low abundance of desmosterol in 3-week-old DHCR $24^{-1-}$ mice were associated with major changes in distribution of raft proteins and altered lipid composition of DRMs, challenging the very existence of lipid rafts in these mice. In contrast, high levels of desmosterol in 16-week-old DHCR $24^{-1-}$ mice allowed desmosterol-DRM formation and protein recruitment of raft marker in these domains, strongly suggesting that, at equimolar concentrations, desmosterol can replace cholesterol resulting in normal membrane integrity and proper DRM organization.

Our data show that extensive cholesterol depletion in 3 -week-old DHCR $24^{-1-}$ brains led to lower $\beta$-cleavage and diminished $\mathrm{A} \beta$ production. The reduced activity of $\mathrm{BACE}$ and the $\gamma$-secretase complex suggest that defective membrane composition in brains of 3 -week-old DHCR24 $4^{-/-}$ mice insufficiently maintained enzymatic activity of the two secretases, which is likely to contribute to the observed changes in $\mathrm{A} \beta$ generation in these mice. This interpretation is in line with several previous findings showing that disrupted cholesterol transport can alter subcelluar distribution of presenilin and change APP processing [35, 50], and that depletion of membrane cholesterol results in complete inhibition of $\gamma$-secretase cleavage of APP [51]. Moreover, it was shown that alterations in $\beta$-secretase activity might be responsible for the dependence of $\mathrm{A} \beta$ production on cholesterol levels. Crosslinking experiments of APP and BACE in raft domains [21] and targeting of BACE to rafts [22] remarkably affect $\mathrm{A} \beta$ production in a cholesterol dependentmanner. In 16 -week-old DHCR24 $4^{-1-}$ mice, full $\beta$ - and $\gamma$-secretase activity was observed, indicating that desmosterol membrane repartition in place of cholesterol allows normal BACE and gamma-secretase complex functioning.

It has been previously shown that cholesterol content correlates with BACE activity in proteoliposomes. Specific activity of BACE increased twofold in vesicles containing $15 \% \mathrm{w} / \mathrm{w}$ cholesterol relative to cholesterol-free vesicles [36]. The effect of desmosterol was investigated in a similar system. Desmosterol was found to be effective in supporting BACE activity in this reconstituted system to an extent similar to cholesterol, while the effect of 7-ketocholesterol was much weaker. These data support the concept in which cholesterol and its closely related derivatives that exhibit similar physico-chemical properties in lipid mixtures relevant to physiological membranes play an important role in supporting $\mathrm{BACE}$ activity and hence $\mathrm{A} \beta$ formation.

Inborn errors of cholesterol synthesis cause human malformation syndromes [52]. It is still a matter of debate, whether the malformations result from lacking cholesterol concentrations during development or from the buildup of the respective precursor. Therefore, the effect of cholesterol loss and its substitution by various precursors was investigated intensively during the last years either using model membranes [17, 18, 49, 53, 54], employing biological membranes treated with cholesterol extracting agents and/or sterol intermediates [55, 56] or applying inhibitors targeting specific reductases in the cholesterol biosynthesis pathway [19, 57-59]. DHCR24-knock-outs are the first viable cholesterol-free mice. Their mild phenotype, being small and infertile, is in marked contrast to the severe inborn defects of human desmosterolosis patients who display an insufficient cholesterol reductase activity due to mutations in the $d h c r 24$ gene $[6,60]$. This marked difference might be explained by the availability of maternal cholesterol during mouse embryonic development [9, 61]. However, desmosterol accumulation per se does not seem to cause adverse health effects [56].

In model membranes, the influence of desmosterol on lipid order was shown to be similar to that of cholesterol and both sterols seem to affect lipid packing to a comparable extent [17]. On a functional level, desmosterol was shown to activate LXR-targeted genes in vitro [49] and in vivo [61] and to substitute for cholesterol in the developing and neonatal rat retina [58]. However, it was shown that desmosterol in model membranes promotes the formation and stability of ordered domains somewhat less efficiently than cholesterol $[53,55]$, and recent data show that 
inhibition of 24-dehydrocholesterol reductase in HeLa cells increases the structural heterogeneity of caveolae due to a decreased affinity of caveolin-1 for sterol and a reduced stability of caveolin oligomers [19]. Nevertheless, substitution of cholesterol by desmosterol does not affect membrane integrity or caveolar invagination and caveolar ligand uptake is only moderately inhibited in these cells [19]. Vainio et al. [55] found that in mammalian cell membranes desmosterol associated less avidly than cholesterol with DRMs. Their model is different from ours in that they use $\mathrm{CHO}$ cells containing high amounts of endogenous desmosterol concentrations, but normal levels of cholesterol, therefore the presence of cholesterol is likely to affect desmosterol-DRM association. Despite this difference, our results are consistent with the idea that desmosterol is capable to associate with DRMs. Furthermore, Vainio et al. also showed that exchanging of $\sim 70 \%$ of cholesterol by desmosterol in mammalian cell membranes using methyl$\beta$-cyclodextrin impaired raft-dependent signaling via the insulin receptor, whereas protein secretion, a process highly dependent on membrane composition and properties [62], was not affected by cholesterol substitution with desmosterol. These findings suggest that short-term, methyl$\beta$-cyclodextrin-mediated cholesterol replacement in membranes may influence certain raft-dependent functions while others remain unaffected. Using a cellular model in which endogenous desmosterol replaces cholesterol, reaching a steady state, we show that APP processing and A $\beta$ generation are not affected, and the distribution and the internalization of plasma membrane GM1 are comparable to cholesterol containing membranes. Moreover, we found no significant differences in membrane receptor ligand binding and activation, and regulation of membrane protein proteolytic activity between 16 -week-old DHCR $24^{-/-}$and wt mice, confirming the functional activity of endogenous desmosterol containing membranes in 16-week-old DHCR24 ${ }^{-1-}$ brains.

In conclusion, our data support the concept that proper raft organization is required to maintain physiological APP processing and $\mathrm{A} \beta$ generation, and they show that desmosterol is capable of substituting for cholesterol and taking over its role in membrane structure, raft-formation and membrane-related processes in vivo.

Acknowledgments We thank Dr. E. Feinstein (Quark Biotech Inc.) for providing the DHCR24 deficient mice and Takeda Pharmaceutical Company Limited for providing the anti-A $\beta$ antibodies for the murine A $\beta$ ELISA. We thank E. Biondi for technical assistance. This work was supported by grants from the Swiss National Science Foundation \#3200BO-112616 and 451NF40-111381 (NCCR Neuro), the University of Zurich, the Swiss Academy of Medical Sciences, Hermann Klaus, Hartmann Müller and the Novartis Foundations to MHM, Regione Piemonte to MDL, by grants of the US National Institutes of Health to FLH (NINDS R01 NS046006), and by EU grant LSHMCT-2003-503330 (APOPIS) and DFGSFB6027 to RMN.

\section{References}

1. Bloch KE (1983) Sterol structure and membrane function. CRC Crit Rev Biochem 14(1):47-92. doi:10.3109/10409238309102790

2. Simons K, Toomre D (2000) Lipid rafts and signal transduction. Nat Rev Mol Cell Biol 1(1):31-39. doi:10.1038/35036052

3. Wood WG, Schroeder F, Igbavboa U et al (2002) Brain membrane cholesterol domains, aging and amyloid beta-peptides. Neurobiol Aging 23(5):685-694. doi:10.1016/S0197-4580(02)00018-0

4. Ledesma MD, Abad-Rodriguez J, Galvan C et al (2003) Raft disorganization leads to reduced plasmin activity in Alzheimer's disease brains. EMBO Rep 4(12):1190-1196. doi:10.1038/sj.embor. 7400021

5. Simons K, Ehehalt R (2002) Cholesterol, lipid rafts, and disease. J Clin Invest 110(5):597-603

6. Waterham HR, Koster J, Romeijn GJ et al (2001) Mutations in the 3beta-hydroxysterol delta24-reductase gene cause desmosterolosis, an autosomal recessive disorder of cholesterol biosynthesis. Am J Hum Genet 69(4):685-694. doi:10.1086/323473

7. Crameri A, Biondi E, Kuehnle K et al (2006) The role of seladin1/DHCR24 in cholesterol biosynthesis, APP processing and Abeta generation in vivo. EMBO J 25(2):432-443. doi:10.1038/sj. emboj.7600938

8. Ohyama Y, Meaney S, Heverin M et al (2006) Studies on the transcriptional regulation of cholesterol 24-hydroxylase (CYP46A1): marked insensitivity toward different regulatory axes. J Biol Chem 281(7):3810-3820. doi:10.1074/jbc.M505179200

9. Wechsler A, Brafman A, Shafir M et al (2003) Generation of viable cholesterol-free mice. Science 302(5653):2087. doi:10.1126/science. 1090776

10. Simons K, Ikonen E (1997) Functional rafts in cell membranes. Nature 387(6633):569-572. doi:10.1038/42408

11. Pike LJ (2006) Rafts defined: a report on the keystone symposium on lipid rafts and cell function. J Lipid Res 47(7):1597-1598. doi: 10.1194/jlr.E600002-JLR200

12. Schroeder R, London E, Brown D (1994) Interactions between saturated acyl chains confer detergent resistance on lipids and glycosylphosphatidylinositol (GPI)-anchored proteins: GPIanchored proteins in liposomes and cells show similar behavior. Proc Natl Acad Sci USA 91(25):12130-12134. doi:10.1073/pnas. 91.25.12130

13. Barenholz Y (2002) Cholesterol and other membrane active sterols: from membrane evolution to "rafts". Prog Lipid Res 41(1):1-5. doi:10.1016/S0163-7827(01)00016-9

14. Stottrup BL, Keller SL (2006) Phase behavior of lipid monolayers containing DPPC and cholesterol analogs. Biophys J 90(9): 3176-3183. doi:10.1529/biophysj.105.072959

15. Lusa S, Heino S, Ikonen E (2003) Differential mobilization of newly synthesized cholesterol and biosynthetic sterol precursors from cells. J Biol Chem 278(22):19844-19851. doi:10.1074/jbc. M212503200

16. Wang J, Megha, London E (2004) Relationship between sterol/ steroid structure and participation in ordered lipid domains (lipid rafts): implications for lipid raft structure and function. Biochemistry 43(4):1010-1018. doi:10.1021/bi035696y

17. Huster D, Scheidt HA, Arnold K et al (2005) Desmosterol may replace cholesterol in lipid membranes. Biophys J 88(3):18381844. doi:10.1529/biophysj.104.048926

18. Shrivastava S, Paila YD, Dutta A et al (2008) Differential effects of cholesterol and its immediate biosynthetic precursors on membrane organization. Biochemistry 47(20):5668-5677. doi:10.1021/ bi8001677

19. Jansen M, Pietiainen VM, Polonen H et al (2008) Cholesterol substitution increases the structural heterogeneity of caveolae. J Biol Chem 283(21):14610-14618. doi:10.1074/jbc.M710355200 
20. Selkoe DJ (2001) Alzheimer's disease: genes, proteins, and therapy. Physiol Rev 81(2):741-766

21. Ehehalt R, Keller P, Haass C et al (2003) Amyloidogenic processing of the Alzheimer beta-amyloid precursor protein depends on lipid rafts. J Cell Biol 160(1):113-123. doi:10.1083/jcb.200207 113

22. Cordy JM, Hussain I, Dingwall C et al (2003) Exclusively targeting beta-secretase to lipid rafts by GPI-anchor addition up-regulates beta-site processing of the amyloid precursor protein. Proc Natl Acad Sci USA 100(20):11735-11740. doi:10.1073/pnas.16351 30100

23. Riddell DR, Christie G, Hussain I et al (2001) Compartmentalization of beta-secretase (Asp2) into low-buoyant density, noncaveolar lipid rafts. Curr Biol 11(16):1288-1293. doi:10.1016/ S0960-9822(01)00394-3

24. Vetrivel KS, Cheng H, Lin W et al (2004) Association of gammasecretase with lipid rafts in post-Golgi and endosome membranes. J Biol Chem 279(43):44945-44954. doi:10.1074/jbc.M407986200

25. Abad-Rodriguez J, Ledesma MD, Craessaerts K et al (2004) Neuronal membrane cholesterol loss enhances amyloid peptide generation. J Cell Biol 167(5):953-960. doi:10.1083/jcb.200404149

26. Kaether C, Haass C (2004) A lipid boundary separates APP and secretases and limits amyloid beta-peptide generation. J Cell Biol 167(5):809-812. doi:10.1083/jcb.200410090

27. Kojro E, Gimpl G, Lammich S et al (2001) Low cholesterol stimulates the nonamyloidogenic pathway by its effect on the alpha -secretase ADAM 10. Proc Natl Acad Sci USA 98(10): 5815-5820. doi:10.1073/pnas.081612998

28. Parvathy S, Ehrlich M, Pedrini S et al (2004) Atorvastatin-induced activation of Alzheimer's alpha secretase is resistant to standard inhibitors of protein phosphorylation-regulated ectodomain shedding. J Neurochem 90(4):1005-1010. doi:10.1111/j.1471-4159. 2004.02521.x

29. Refolo LM, Pappolla MA, LaFrancois J et al (2001) A cholesterol-lowering drug reduces beta-amyloid pathology in a transgenic mouse model of Alzheimer's disease. Neurobiol Dis 8(5):890-899. doi:10.1006/nbdi.2001.0422

30. Simons M, Keller P, De Strooper B et al (1998) Cholesterol depletion inhibits the generation of beta-amyloid in hippocampal neurons. Proc Natl Acad Sci USA 95(11):6460-6464. doi:10.1073/ pnas.95.11.6460

31. Banker G, Goslin K (1991) Culturing nerve cells. Cellular and molecular neuroscience series, 2nd edn. MIT, Cambridge, $453 \mathrm{pp}$

32. Fukumoto H, Cheung BS, Hyman BT et al (2002) Beta-secretase protein and activity are increased in the neocortex in Alzheimer disease. Arch Neurol 59(9):1381-1389. doi:10.1001/archneur.59.9.1381

33. Bligh EG, Dyer WJ (1959) A rapid method of total lipid extraction and purification. Can J Biochem Physiol 37(8):911-917

34. Lutjohann D, Brzezinka A, Barth E et al (2002) Profile of cholesterol-related sterols in aged amyloid precursor protein transgenic mouse brain. J Lipid Res 43(7):1078-1085. doi:10.1194/jlr.M200 071-JLR200

35. Burns M, Gaynor K, Olm V et al (2003) Presenilin redistribution associated with aberrant cholesterol transport enhances betaamyloid production in vivo. J Neurosci 23(13):5645-5649

36. Kalvodova L, Kahya N, Schwille P et al (2005) Lipids as modulators of proteolytic activity of BACE: involvement of cholesterol, glycosphingolipids, and anionic phospholipids in vitro. J Biol Chem 280(44):36815-36823. doi:10.1074/jbc.M504484200

37. Greeve I, Hermans-Borgmeyer I, Brellinger C et al (2000) The human DIMINUTO/DWARF1 homolog seladin-1 confers resistance to Alzheimer's disease-associated neurodegeneration and oxidative stress. J Neurosci 20(19):7345-7352

38. Kuehnle K, Crameri A, Kalin RE et al. (2008) Prosurvival effect of DHCR24/Seladin-1 in acute and chronic responses to oxidative stress. Mol Cell Biol 28(2):539-550
39. Wu C, Miloslavskaya I, Demontis S et al (2004) Regulation of cellular response to oncogenic and oxidative stress by Seladin-1. Nature 432(7017):640-645. doi:10.1038/nature03173

40. Collen D (1999) The plasminogen (fibrinolytic) system. Thromb Haemost 82(2):259-270

41. Plow EF, Herren T, Redlitz A et al (1995) The cell biology of the plasminogen system. FASEB J 9(10):939-945

42. Ledesma MD, Da Silva JS, Schevchenko A et al (2003) Proteomic characterisation of neuronal sphingolipid-cholesterol microdomains: role in plasminogen activation. Brain Res 987(1): 107-116. doi:10.1016/S0006-8993(03)03296-7

43. Ledesma MD, Da Silva JS, Crassaerts K et al (2000) Brain plasmin enhances APP alpha-cleavage and Abeta degradation and is reduced in Alzheimer's disease brains. EMBO Rep 1(6):530-535

44. Massey JB, Pownall HJ (2005) The polar nature of 7-ketocholesterol determines its location within membrane domains and the kinetics of membrane microsolubilization by apolipoprotein A-I. Biochemistry 44(30):10423-10433. doi:10.1021/bi0506425

45. Mayor S, Pagano RE (2007) Pathways of clathrin-independent endocytosis. Nat Rev Mol Cell Biol 8(8):603-612. doi:10.1038/ nrm2216

46. Merritt EA, Sarfaty S, van den Akker F et al (1994) Crystal structure of cholera toxin B-pentamer bound to receptor GM1 pentasaccharide. Protein Sci 3(2):166-175

47. Boogaard A, Griffioen M, Cohen LH (1987) Regulation of 3hydroxy-3-methylglutaryl-coenzyme A reductase in human hepatoma cell line Hep G2. Effects of inhibitors of cholesterol synthesis on enzyme activity. Biochem J 241(2):345-351

48. Song BL, Javitt NB, DeBose-Boyd RA (2005) Insig-mediated degradation of $\mathrm{HMG}$ CoA reductase stimulated by lanosterol, an intermediate in the synthesis of cholesterol. Cell Metab 1(3):179189. doi:10.1016/j.cmet.2005.01.001

49. Yang C, McDonald JG, Patel A et al (2006) Sterol intermediates from cholesterol biosynthetic pathway as liver $\mathrm{X}$ receptor ligands. J Biol Chem 281(38):27816-27826. doi:10.1074/jbc.M603781200

50. Runz H, Rietdorf J, Tomic I et al (2002) Inhibition of intracellular cholesterol transport alters presenilin localization and amyloid precursor protein processing in neuronal cells. J Neurosci 22(5): 1679-1689

51. Wahrle S, Das P, Nyborg AC et al (2002) Cholesterol-dependent gamma-secretase activity in buoyant cholesterol-rich membrane microdomains. Neurobiol Dis 9(1):11-23. doi:10.1006/nbdi. 2001.0470

52. Porter FD (2002) Malformation syndromes due to inborn errors of cholesterol synthesis. J Clin Invest 110(6):715-724

53. Megha, Bakht O, London E (2006) Cholesterol precursors stabilize ordinary and ceramide-rich ordered lipid domains (lipid rafts) to different degrees. Implications for the Bloch hypothesis and sterol biosynthesis disorders. J Biol Chem 281(31):21903-21913. doi: 10.1074/jbc.M600395200

54. Samuli Ollila OH, Rog T, Karttunen M et al (2007) Role of sterol type on lateral pressure profiles of lipid membranes affecting membrane protein functionality: comparison between cholesterol, desmosterol, 7-dehydrocholesterol and ketosterol. J Struct Biol 159(2):311-323. doi:10.1016/j.jsb.2007.01.012

55. Vainio S, Jansen M, Koivusalo M et al (2006) Significance of sterol structural specificity. Desmosterol cannot replace cholesterol in lipid rafts. J Biol Chem 281(1):348-355. doi:10.1074/jbc. M509530200

56. Xu F, Rychnovsky SD, Belani JD et al (2005) Dual roles for cholesterol in mammalian cells. Proc Natl Acad Sci USA 102(41): 14551-14556. doi:10.1073/pnas.0503590102

57. Aufenanger J, Pill J, Schmidt FH et al (1986) The effects of BM 15.766, an inhibitor of 7-dehydrocholesterol delta 7-reductase, on cholesterol biosynthesis in primary rat hepatocytes. Biochem Pharmacol 35(6):911-916. doi:10.1016/0006-2952(86)90076-6 
58. Fliesler SJ, Richards MJ, Miller CY et al (2000) Cholesterol synthesis in the vertebrate retina: effects of U18666A on rat retinal structure, photoreceptor membrane assembly, and sterol metabolism and composition. Lipids 35(3):289-296. doi:10.1007/ s11745-000-0525-y

59. Keller RK, Arnold TP, Fliesler SJ (2004) Formation of 7-dehydrocholesterol-containing membrane rafts in vitro and in vivo, with relevance to the Smith-Lemli-Opitz syndrome. J Lipid Res 45(2):347-355. doi:10.1194/jlr.M300232-JLR200

60. Andersson HC, Kratz L, Kelley R (2002) Desmosterolosis presenting with multiple congenital anomalies and profound developmental delay. Am J Med Genet 113(4):315-319. doi:10.1002/ajmg.b.10873
61. Heverin M, Meaney S, Brafman A et al (2007) Studies on the cholesterol-free mouse: strong activation of LXR-regulated hepatic genes when replacing cholesterol with desmosterol. Arterioscler Thromb Vasc Biol 27(10):2191-2197. doi:10.1161/ ATVBAHA.107.149823

62. Gondre-Lewis MC, Petrache HI, Wassif CA et al (2006) Abnormal sterols in cholesterol-deficiency diseases cause secretory granule malformation and decreased membrane curvature. J Cell Sci 119(Pt 9):1876-1885. doi:10.1242/jcs.02906

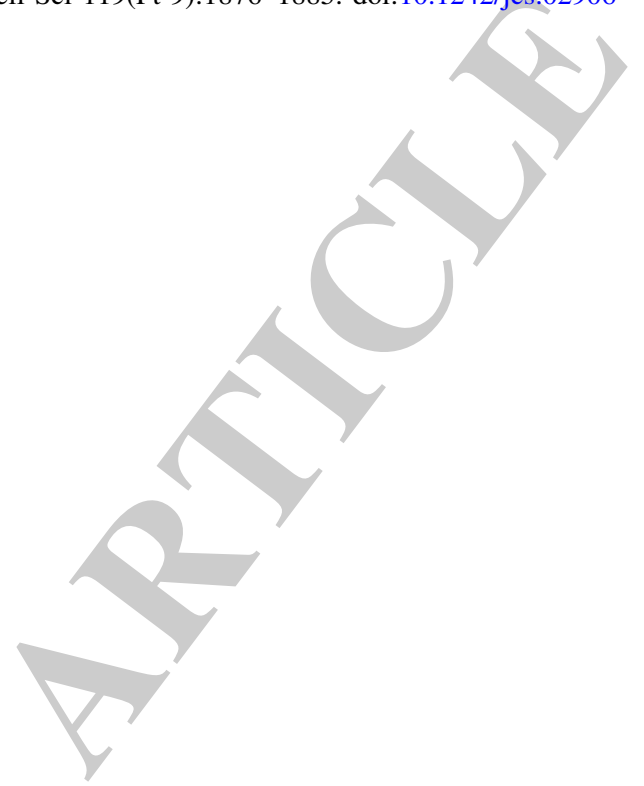

